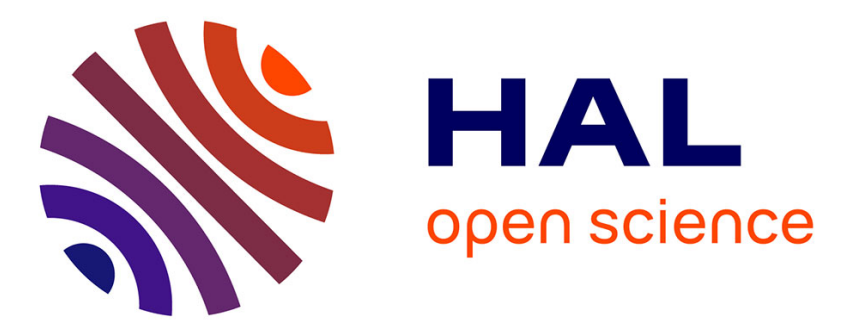

\title{
Product design-Process selection-Process planning Integration based on Modeling and Simulation
}

\author{
von Dim Nguyen, Patrick Martin
}

\section{To cite this version:}

von Dim Nguyen, Patrick Martin. Product design-Process selection-Process planning Integration based on Modeling and Simulation. International Journal of Advanced Manufacturing Technology, 2015, 77 (1-4), pp.187-201. 10.1007/s00170-014-6446-7 . hal-01943179

\section{HAL Id: hal-01943179 \\ https://hal.science/hal-01943179}

Submitted on 3 Dec 2018

HAL is a multi-disciplinary open access archive for the deposit and dissemination of scientific research documents, whether they are published or not. The documents may come from teaching and research institutions in France or abroad, or from public or private research centers.
L'archive ouverte pluridisciplinaire HAL, est destinée au dépôt et à la diffusion de documents scientifiques de niveau recherche, publiés ou non, émanant des établissements d'enseignement et de recherche français ou étrangers, des laboratoires publics ou privés. 


\title{
Product design-process selection-process planning integration based on modeling and simulation
}

\author{
Von Dim Nguyen • Patrick Martin
}

\begin{abstract}
As a solution for traditional design process having many drawbacks in the manufacturing process, the integration of product design-process selection-process planning is carried out in the early design phase. The technological, economic, and logistic parameters are taken into account simultaneously as well as manufacturing constraints being integrated into the product design. As a consequence, the most feasible alternative with regard to the product's detailed design is extracted, satisfying the product's functional requirements. Subsequently, a couple of conceptual process plans are proposed relied on manufacturing processes being preliminarily selected in the conceptual design phase. Virtual manufacturing is employed under CAM software to simulate fabrication process of the potential process plans. Ultimately, the most suitable process plan for fabricating the part is recommended based upon a multi-criteria analysis as a resolution for decision-making.
\end{abstract}

Keywords Modeling · Simulation · Product design · Process selection $\cdot$ Process planning

\section{Introduction}

1.1 Context

In a context where it is necessary to respond industrial challenges towards shorter lead times, lower cost and better customer satisfaction. Concurrent engineering (CE) was born as a solution to these issues. The solution of the $\mathrm{CE}$ is carried out in a manner that the different tasks in the product and production development process are integrated and performed at the same time rather than in sequence. Due to the tasks being implemented in parallel, by integrating product and process design, this makes a decrease the development lead time and enhances the quality [1]. Thus, application of concurrent engineering as well as integration of product and process in production is necessary to be carried out.

In order to do this, it is essential to take into consideration the product's specifications and the constraints of manufacturing process in the design phase. Presently, the design process concentrates on the geometric model built from the choice of architecture to respond the structural features of a product. However, these CAD models merely represent the information in respect to the product's nominal geometry after that they might not relate to fabrication process or will cause the difficulties in process planning. For resolving these problems, design for manufacture (DFM) was proposed with the purpose that combining the manufacturing information into the product in the product definition stage [2]. By using this approach, many problems are avoided thanks to taking into account the manufacturing constraints during the product design phase. In order to implement the integrated engineering of DFM approach (or minimum engagement principle or best least 
Fig. 1 Concurrent engineering as expressed by prime European region $[\mathrm{S} 1]$

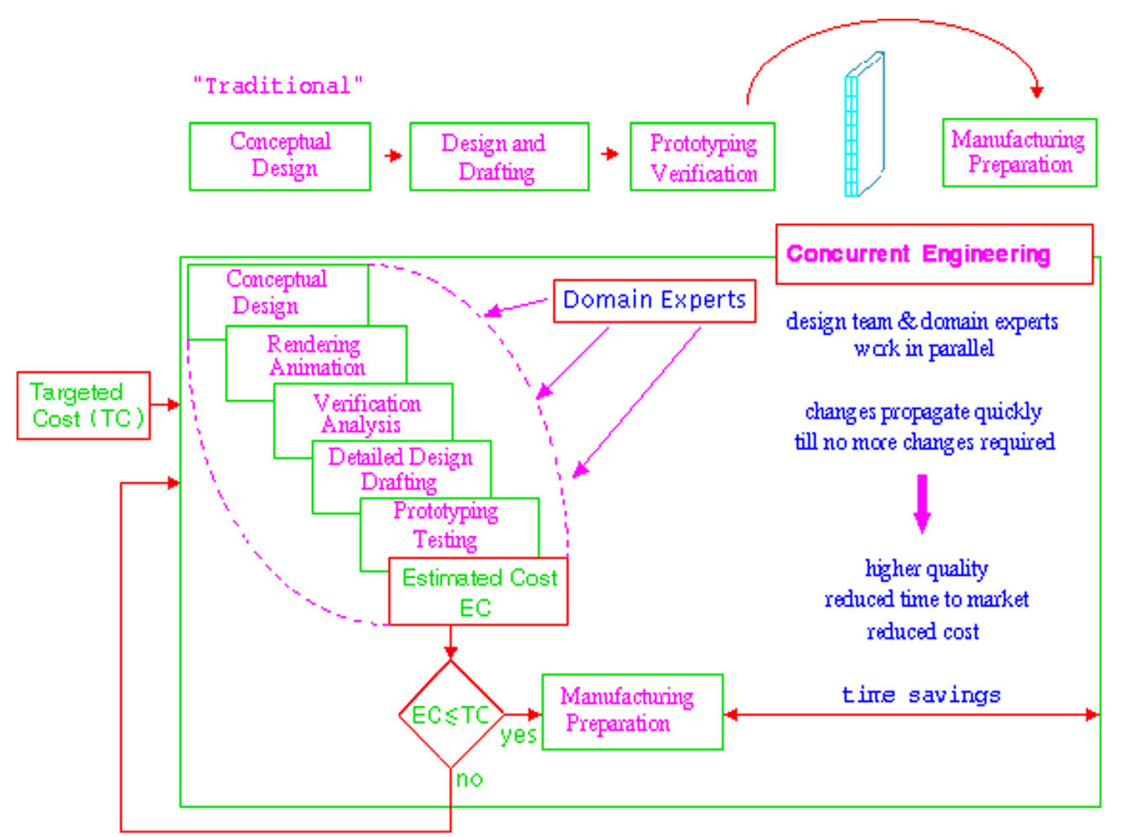

commitment), it is fundamental to formalize and structure the knowledge of manufacturing process such as the rules as well as criteria in selection of fabrication process so as to integrate in the definition of product. Due to the fact that corresponding to the various products, different process plans are created. Consequently, the data of manufacturing process structured and formalized is necessary for manipulation in the process of product definition and selection of fabricating methods. Nevertheless, a product can be manufactured by using a process or several processes being generated process plans. Thus, conceptual process planning has to take into account in the early design stage. Traditionally, the design process flows in sequence; as a consequence, manufacturing processes are determined from the choices which were assigned in the product definition without taking into consideration manufacturing constraints. At manufacturing preparation stage, these problems will be able to trouble process planners, and in turn results in unpredictable difficulties in production process.

To overcome the drawbacks of the traditional design model, we adopt an approach of integrated design, in particular design for manufacture, which allows simultaneous addition of activities integrating manufacturing constraints. Moreover, estimating manufacturing cost and lead time in production process are also integrated in the design process. This concurrent engineering design method starts with a target cost for the product, which the traditional design method has no such thing. Afterwards, the estimated cost of the product design and the targeted cost are compared to each other. The production process can be only deployed if the estimated cost is lower or equal to the targeted cost. The illustration of the concurrent engineering design is shown in Fig. 1.

In the framework of concurrent engineering and DFM, this paper proposes an approach contributing to integrated design in which product design, its manufacturing process selection, and process planning are carried out in parallel. This contributes to the development of integrated design tools such as CAD/CAM and computer-aided process planning (CAPP), [3-5].

\subsection{Issue and objective}

Currently, there are several approaches as well as informatics applications dedicated to selecting manufacturing processes in order to meet the product's technical and geometrical characteristics which have been proposed by scientific community as shown in Table 1.

However, these approaches and applications only take into account specifications for finishing the product. In other words, they just support for the selection of manufacturing process corresponding to each features' specifications belonging to a product, as well as mechanical products being fabricated by a manufacturing process. On the other hand, in practice, process planning with the sequence of manufacturing 
Table 1 Comparison of the approaches "manufacturing processes selection" [6]

\begin{tabular}{lllll}
\hline Approach & $\begin{array}{l}\text { Choice of } \\
\text { manufacturing } \\
\text { processes }\end{array}$ & $\begin{array}{l}\text { Choice of } \\
\text { materials }\end{array}$ & $\begin{array}{l}\text { Associated } \\
\text { tool }\end{array}$ & $\begin{array}{l}\text { Economical } \\
\text { evaluation }\end{array}$ \\
\hline Ishii & Yes & No & HyperQ/process & Yes \\
Ashby & Yes & Yes & CES & n.a. \\
Gupta & Yes & Yes & Seer-DFM & Yes \\
Boothroyd & Yes & Yes & DFMA & Yes \\
Lovatt & Yes & n.a. & n.a. & Yes \\
\hline
\end{tabular}

processes is necessary to carry out for yielding complex parts. In particular, complicated parts, for instance, the forward steering part of the Shell Eco-Marathon (MASH) vehicle presented in Fig. 2 owning basic shapes such as disk and tube are considered in this approach.

The main objective of our work is to propose an approach in the scope of integrated design considering typically mechanical parts generated from two basic shapes consisting of disk and tube as shown in Fig. 3. This contributes to the development of generative CAPP systems in which conceptual process plans are generated relied on conditions of elimination of incompatible manufacturing processes with the product design.

This paper discusses two principle matters that are integrated completely in the conceptual design phase. Firstly, dealing with the DFM of typically mechanical parts (made of basic shapes of disk and tube) will be employed. Secondly, taking into consideration generation of conceptual process plans will be also operated.

\section{Methodology and tool used}

\subsection{Methodology}

The main idea of this approach is to carry out the integration of product design and manufacturing process in the early design stage, particularly, from the product's requirements, the analysis, and modeling the product's functional constraints. Afterwards, several product models are created with the simplest entities showing the principal functions of the product. As a result of the functional models, the preliminary selection of manufacturing processes being compatible with the part's characteristics by using dedicated software in terms formalized the manufacturing knowledge. The criteria to select the processes are corresponding to each part's functional feature in which the feature's specifications are preliminarily determined based upon the product's functional requirements. In particular, the intrinsic specifications are taken into account according to this approach such as shape, tolerance, roughness, and material.

As a consequence of the defined manufacturing constraints as well as preliminarily selected manufacturing processes from the dedicated software's output, the product's geometric models and detailed design of which the specifications are assigned consisting of the specific values of dimensions, tolerances, roughness, and type of material applied. Obviously, the integrated design is no longer a sequential method; instead of that, it is an iterative method as synthesis loop. In other words, the information exchanges in relation to the product's properties and manufacturing knowledge are realized between designers, process planners, and manufacturing engineers as well. The major activities of the integrated design process expressed above are rendered with the IDEF- 0 diagram in Fig. 4 [8], where the main activities are decomposed four activities (A1-A4):

- A1: Analyze product's functional requirements. DFM actor must take into consideration the product's demands and identify functional surfaces satisfying product's design requirements.

- A2: Model and characterize product's functional surfaces. Modeling functional surfaces under the form of usage skin and usage skeleton is realized by CAD tools. Features' attributes are represented
Fig. 2 Various proposed design for forward steering part with combination of disk and tube shape [7]

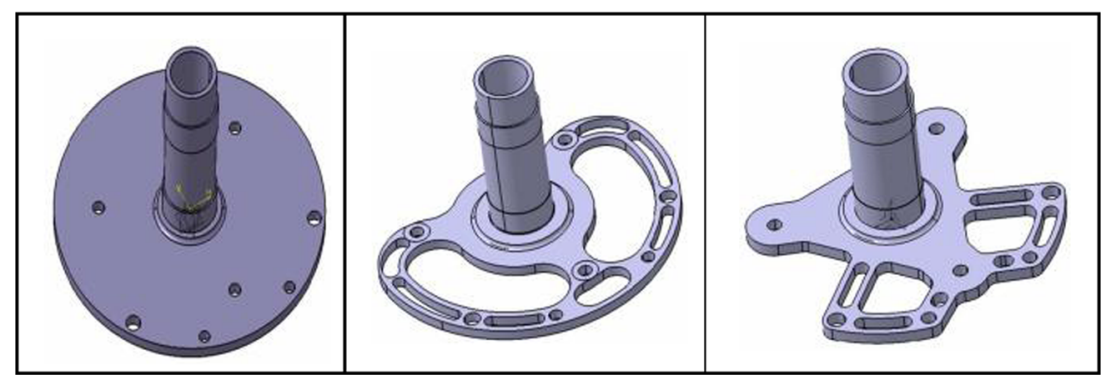


Fig. 3 Basic shapes built up the forward steering part

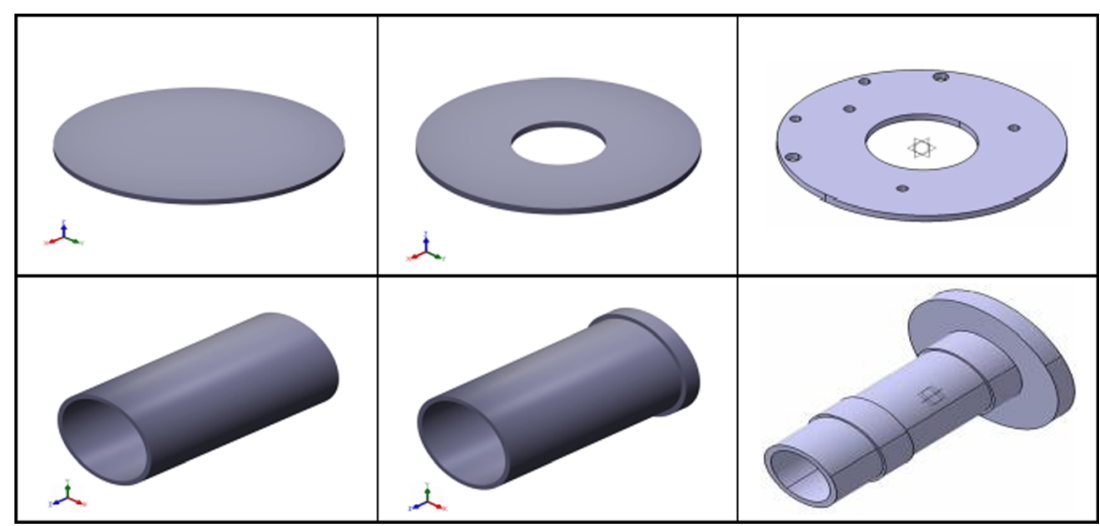

by Unified Modeling Language (UML) classes. Product's alternatives solutions are created as the output of this activity.

- A3: Define manufacturing constraints. This activity proposes manufacturing constraints such as tolerance interval (IT) and surface roughness (Ra) being oriented according to fabrication method. As a result, these manufacturing constraints will be as the constraints to select manufacturing process.

- A4: Select processes and identify manufacturing plans and their constraints. This activity figures out selected manufacturing processes based on the identified

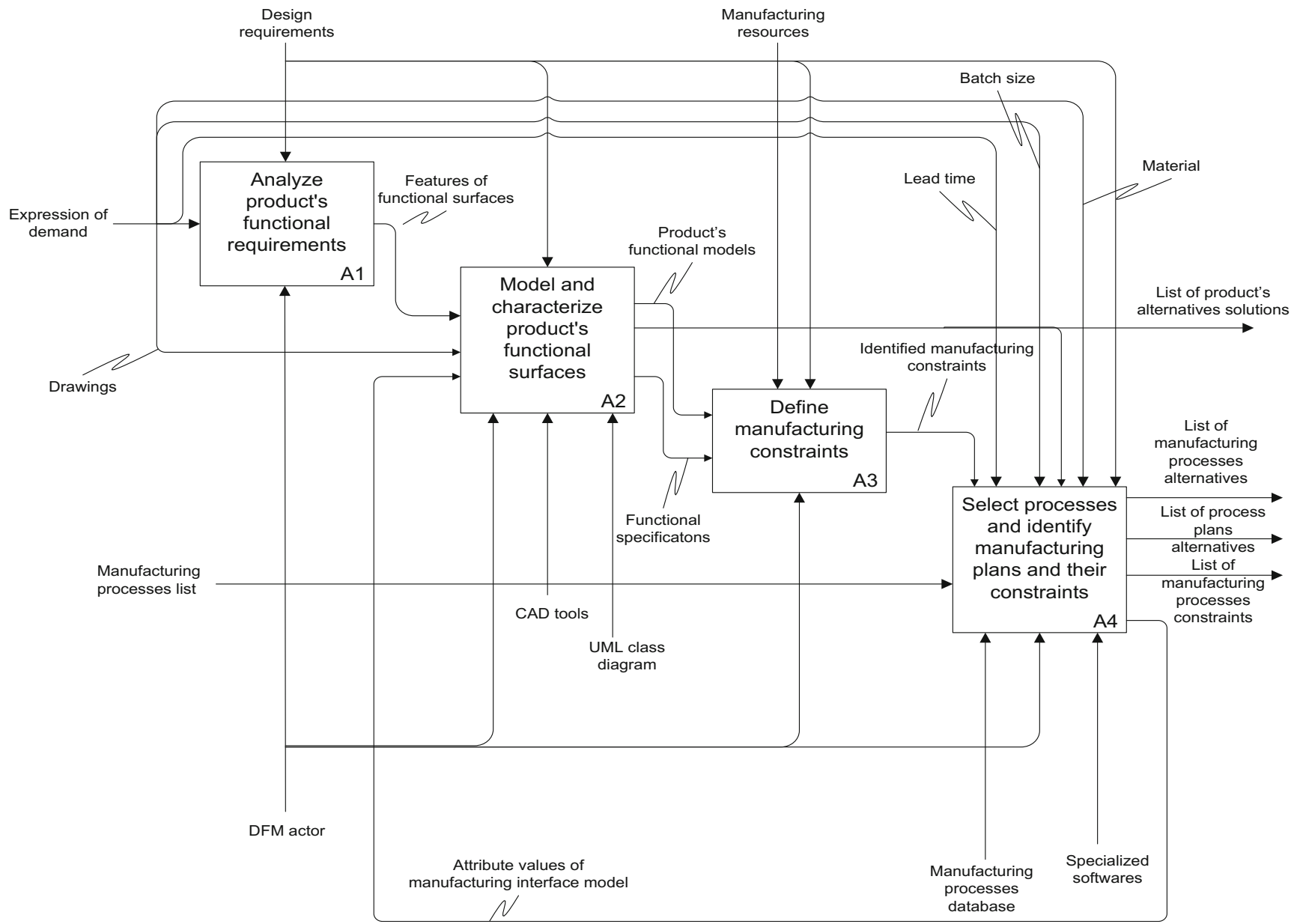

Fig. 4 Main activities of a product's DFM 
constraints. Corresponding to each constraint, processes which are not eligible are eliminated by applying specialized software. As a consequence, a list of fabrication processes is proposed as well as attribute values of manufacturing interface model are integrated to product design.

To be more detailed, the concepts used in the IDEF-0 diagram are extracted as follows:

- Expression of demand: orders from customers such as dimension, batch size, applied loading, lifespan, functional surfaces, and mass

- Global design requirements: constraints with regard to product's specifications as functional characteristics, geometric shape.

- DFM actor: experts who are responsible as designer or process planner.

- Features of functional surfaces: planes that model product's main functions.

- CAD tools: dedicated software such as AutoCAD, Solid works, CATIA.

- UML static structure: one of Unified Modeling Language (UML) diagrams.

- Product's functional models: Functional surfaces of the product are modeled under the form usage skin and usage skeleton.

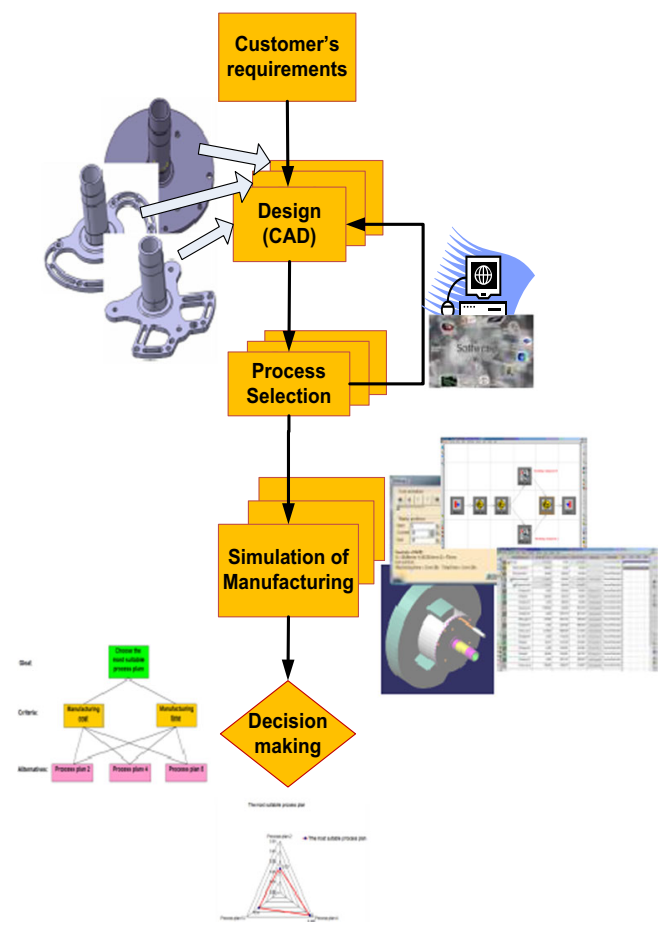

Fig. 5 Proposed integrated design
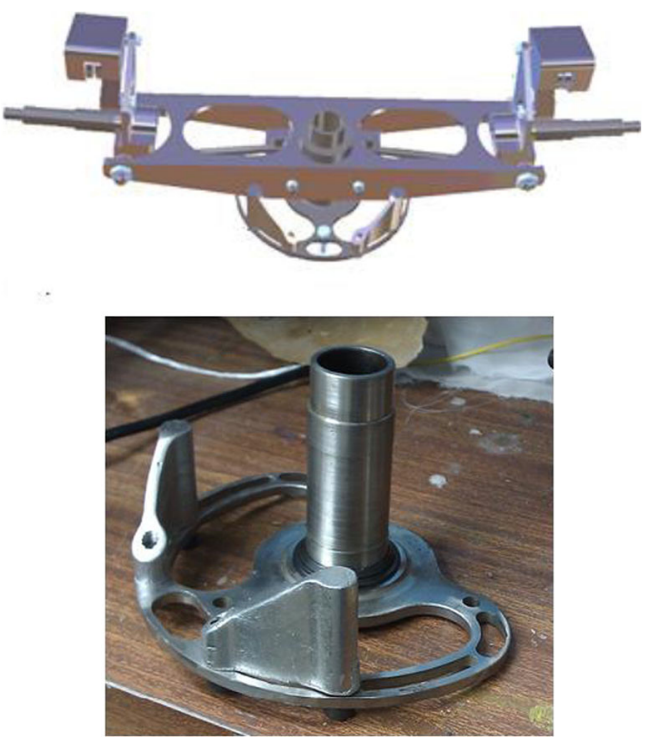

Fig. 6 Forward steering part [7]

- Functional parameters: functional surfaces' attributes such tolerance interval (IT), surface roughness (Ra).

- Manufacturing resources: machine tools or machining centers, tools, equipments such cutting tools, measured devices, and fixtures.

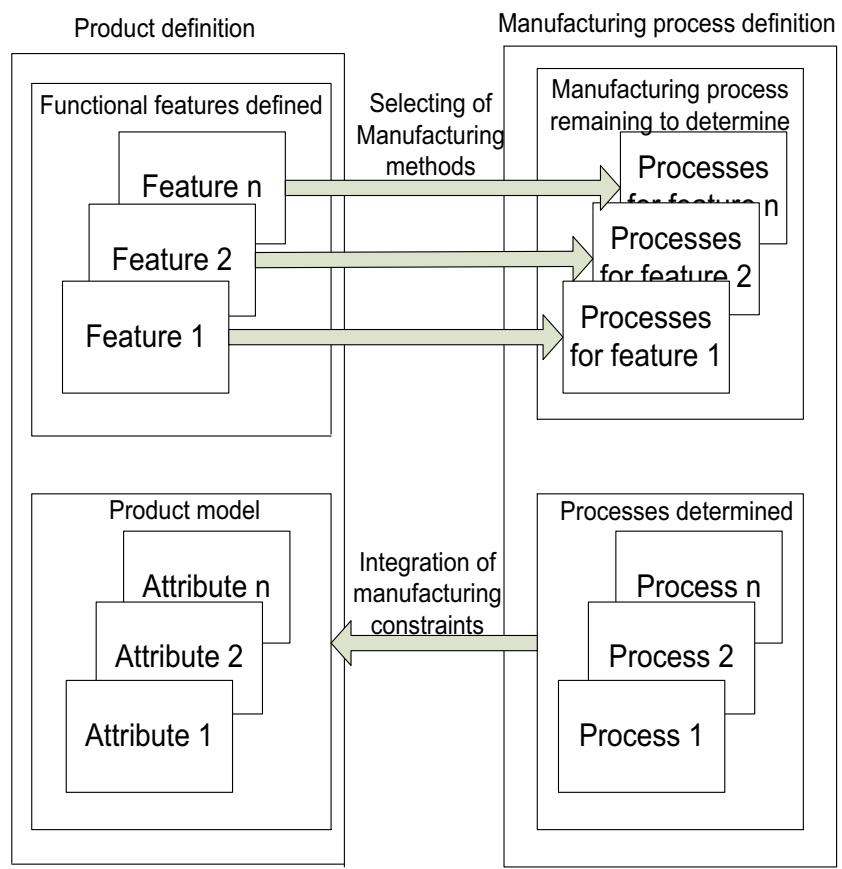

Fig. 7 Integration of design model and manufacturing process selection 
Fig. 8 The forward steering part's design models

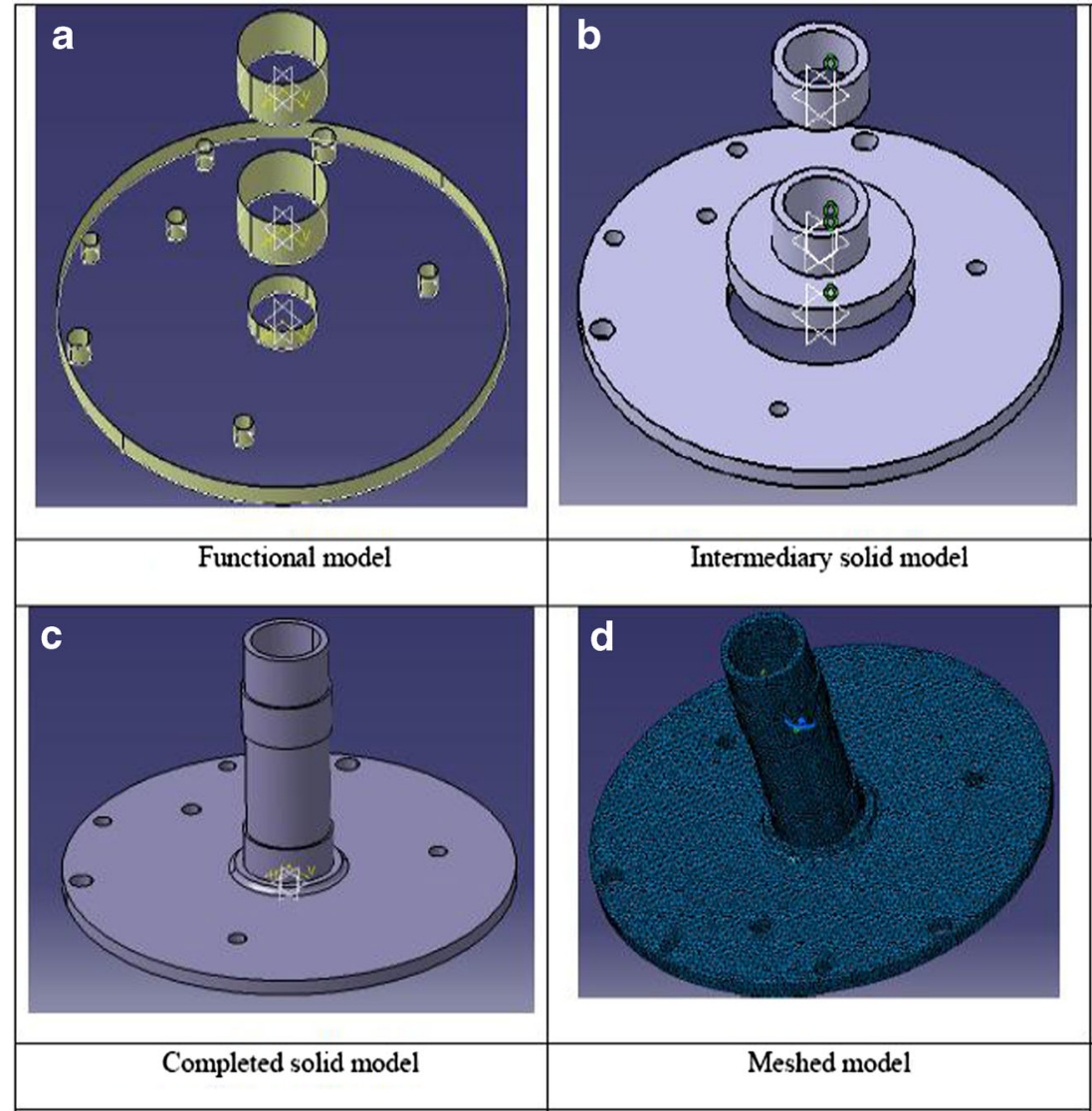

- Identified manufacturing constraints: values of tolerance and roughness are determined.

- Manufacturing processes database: information of process capabilities taken from engineering handbooks or resources from the Internet.

- Specialized software: informatics application tools such as CES EduPack 2010, IP3FR, OMEGAM, custompartnet.com.

- Attributes of manufacturing interface model: surface's characteristics such as tolerance (IT), roughness (Ra), shape, and material proposed from fabrication processes' capabilities.

On the other hand, the principle of manufacturing process selection is relied on the part's functional features of which attributes including tolerance and roughness identified in the ranges being based upon technical requirements.

With the recommended fabrication processes, conceptual process planning is employed in order to propose the alternatives of the part process plans. Subsequently, the proposed process plans are deducted based on the production demands including lead-time, batch-size, economic criteria, and so forth.

As a result, the potential process plans after deduction are simulated by using the CATIA and DELMIA software so as to identify manufacturing time as well as foresee problems being able to occur in manufacturing process. From the simulated results, manufacturing cost estimation is considered applied the activity-based costing $(\mathrm{ABC})$ and cost entity (CE) methods. Finally, in

Table 2 The part's material properties

\begin{tabular}{|c|c|}
\hline Material & Steel \\
\hline Young's modulus & $2 \mathrm{e}+011 \mathrm{~N} / \mathrm{m}^{2}$ \\
\hline \hline Poisson's ratio & 0.266 \\
\hline Density & $7860 \mathrm{~kg} / \mathrm{m}^{3}$ \\
\hline Coefficient of thermal expansion & $1.17 \mathrm{e}-005^{\circ} \mathrm{K}$ \\
\hline \hline Yield strength & $2.5 \mathrm{e}+008 \mathrm{~N} / \mathrm{m}^{2}$ \\
\hline
\end{tabular}




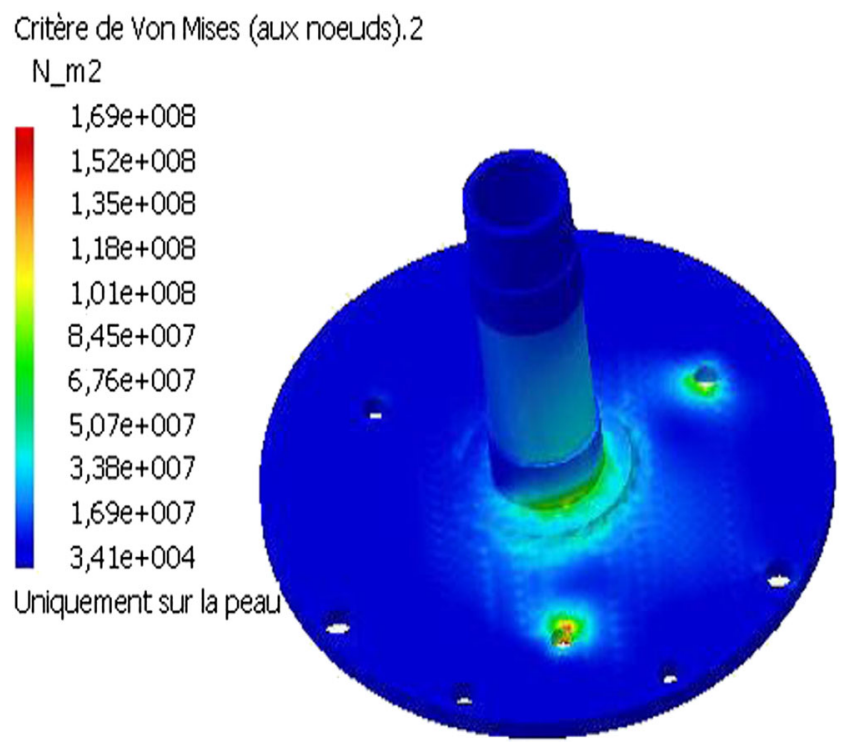

Fig. 9 Analysis of the part's Von Mises stress

order to support for decision-making of the potential process plans in selection of the most suitable plan for fabricating the part, the analytic hierarchy process (AHP) method is used.

Globally, the progress of this proposed approach is presented in the Fig. 5.

\subsection{Tool used}

In order to carry out the proposed methodology, the following several tools are essential to use:

- Modeling languages are used including IDEF0 functional modeling for modeling the product design activities and UML language for modeling the product's features in which its attributes are presented. Flowchart diagram provided by MS Visio is also used to create conceptual process plans. CES
EduPack 2010 and Custompartnet.com software are used for selecting manufacturing processes [9].

- Finite element method (FEM) is served for analyzing the behavior of the part.

- Online integrated cutting data module of Sandvik firm is used in choosing cutting conditions corresponding types of cutting tools.

- CATIA and DELMIA software is applied for modeling the product's models as well as simulating manufacturing process. The DPM module of DELMIA is used for defining digital processes and manufacturing resources.

- The activity-based costing (ABC) and cost entity methods are applied for manufacturing cost estimation. Calculations are executed by MS Excel.

- Analytic hierarchy process (AHP) method is used for making a decision of multiple criteria.

\section{Case study}

The case study is a forward steering part, one of the components of the forward direction system of the Shell Eco-Marathon (MASH) vehicle as presented in Fig. 6. The part must satisfy constraints related to two cylindrical surfaces for wearing the bearings, three holes for fixing the part on the insert, and four holes for fixing the stops on the steering pivot.

It is necessary to take into consideration the weight constraint of the part. Indeed, the principal challenge which needs to be satisfied is that the vehicle travels the furthest on the least amount of energy. Therefore, the design of the part is very important to minimize the part's weight.

\subsection{Analysis and part modeling}

A featured-based model is applied in this case study for process planning where operations of various types are
Table 3 The input data and results from dedicated software

\begin{tabular}{lll}
\hline Function & Input parameters & Output parameters \\
\hline Surfaces for mounting bearings & Shape, circular prismatic & Electric discharge wire cutting \\
& Tolerance, $0.013 \mathrm{~mm}$ & Planning/shaping/slotting \\
& Roughness, 3.2 & \\
Surfaces for mounting bolts & Shape, circular prismatic & Drilling \\
& Tolerance, $0.058 \mathrm{~mm}$ & Milling \\
& Roughness, 6.3 & Planning/shaping/slotting \\
& & Pressing and sintering \\
& & Turning/boring/parting \\
\hline
\end{tabular}


Table 4 The information of the part

The part's information

\begin{tabular}{ll}
\hline Shape group & $\begin{array}{c}\text { Disk shape with unilateral element-no. } \\
213 \text { (ASM handbook classification) }\end{array}$ \\
Material & Alloy steel: 4140 (AISI/SAE) \\
Roughness & Ra 3.2, Ra 6.3 \\
Tolerance & IT10, IT6 (ISO) \\
Max wall thickness & $7 \mathrm{~mm}$ \\
Batch size & 20,000 parts per year
\end{tabular}

directly assigned to specific features without considering their interaction (Fig. 7). Starting from the part's functional requirements, each design feature is assigned with a potential manufacturing process. The specifications of the part are built on the basis of constraints, resources, and manufacturing process capabilities. Integration of design model and manufacturing process selection is shown in Fig. 7.

Based on the part's functional and technical requirements, as well as its constraints with the other components in the system, modeling the part from initial entities relied on its functions to solid models is carried out under CATIA V5 software.

More specifically, the functional model in Fig. 8a is generated under the initial entities in which surfaces are modeled from functional analysis including the surfaces for mounting bearings and hole surfaces for fitting bolts.

From this functional model, several manufacturing processes are selected preliminarily envisaged for fabricating the part. In order to describe the topological entities, solids are added to show clearly the part's geometrical shapes as shown on Fig. 8b. These components are solely restricted the functional constraints, but they are not mounted together. The part's completely geometric model created by connecting the functional solids is rendered as shown in Fig. 8c. This model expresses fully functional requirements of the part and serves as a starting point for process planning.

In addition, in order to verify the behavior and interaction of the part with the forward steering system of the vehicle, finite element analysis (FEA) with the distributed force of $2000 \mathrm{~N}$ exerted on the principal shaft is executed. The analysis is carried out by CATIA software.

The material properties are presented in Table 2. The maximum yield stress of Von Mises which shows maximum stress on the whole is shown in Fig. 9.

As a result from FEA analysis with the CATIA, the maximum Von Mises stress value on the part is $1.68895 \mathrm{e}^{+008} \mathrm{~N} / \mathrm{m}^{2}$, being smaller than the material's yield strength of $2.5 \mathrm{e}^{+008} \mathrm{~N} / \mathrm{m}^{2}$, meaning that the part's material and structure are fulfilled the technical requirements. The part design model is feasible to manufacture.

\subsection{Process selection}

As mentioned in previous section, process selection is realized as soon as the part's functional surfaces are built under the initial entities. In order to support for preliminary selection of manufacturing processes, CES EduPack 2010 software and Custompartnet.com website are applied in which manufacturing knowledge is formalized. Exploitation of the two informatics applications is employed based upon the part's specifications in which specific values of tolerance, roughness, shape, and type of material are entered as the input parameters. As a result, a couple of manufacturing processes are recommended as processes for finishing the part's functional surfaces, satisfying the technical requirements.
Fig. 10 Process planning methods [10]

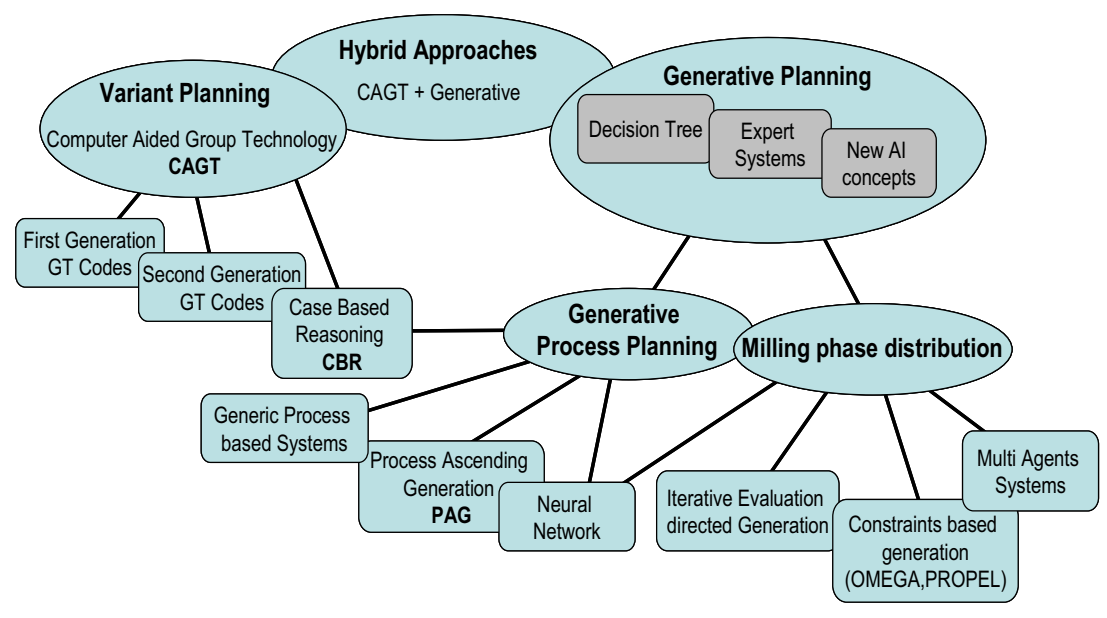




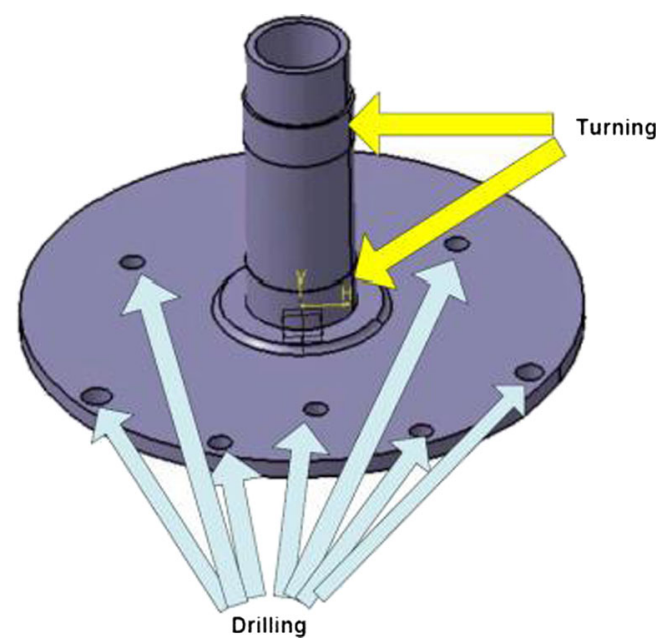

Fig. 11 The part's entities to be machined

In particular, the specifications of the functional surfaces are used as the input parameters for selecting manufacturing processes via dedicated software. For CES EduPack 2010 software, tolerance range fitting, roughness, and part shape are directly entered as input data to get recommended processes. The input data and results are as shown respectively in Table 3.
Apparently, it can be seen that corresponding to each functional surfaces of the part, there are a few eligible manufacturing processes. Consequently, a couple of part designs are generated. Particularly, one of the detailed designs is recommended with the input parameters for process planning being shown in Table 4. The part's engineering drawing is proposed to validate for design as presented on Fig. 12.

\subsection{Process planning}

Generation of process plan is mainly based upon expert system as well as process planner's knowledge and experience which have been mentioned in [10], shown in Fig. 10 . In practice, it also depends on resource of a workshop where it is intended to manufacture the part. Thereby, conceptual process planning would be done with DELMIA; as a result, virtual manufacturing process would be simulated with the purposes of defining manufacturing time and foreseeing unpredictably issues being able to arise during fabrication process.

In order to facilitate for generating conceptual process plans, it is necessary to give types of conditions in which manufacturing processes are incompatible with the product's technical and production requirements.
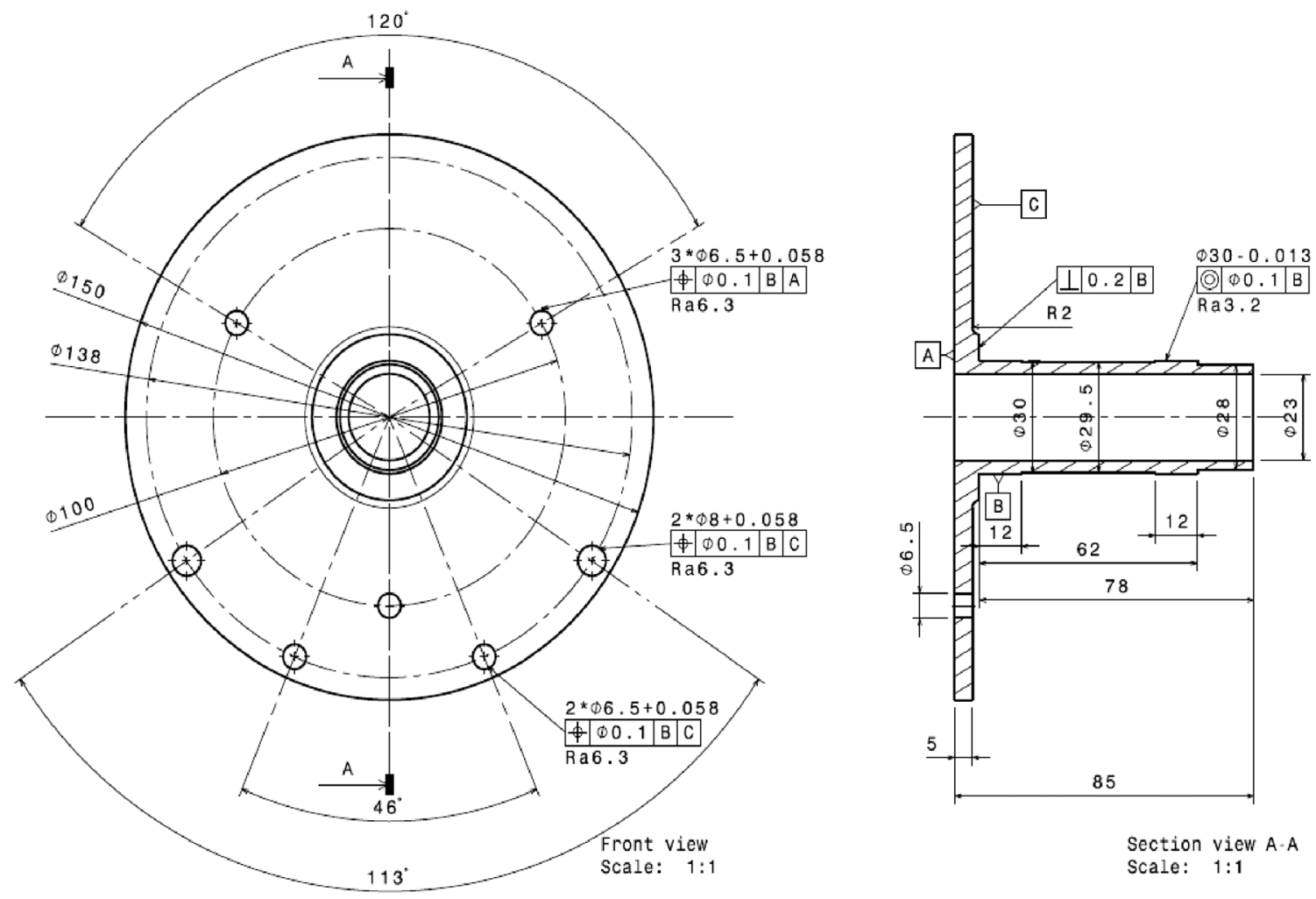

Material: Alloy Steel

Fig. 12 Detailed drawing of the part 
Four types of the conditions have been defined as follows [6]:

- Conditions of elimination relative to the limits of the manufacturing processes
- Conditions of elimination linked to the uselessness of the manufacturing processes

- Conditions of elimination according to the knowledge of an expert

- Conditions of recommendation

Fig. 13 Generating conceptual process plan 2

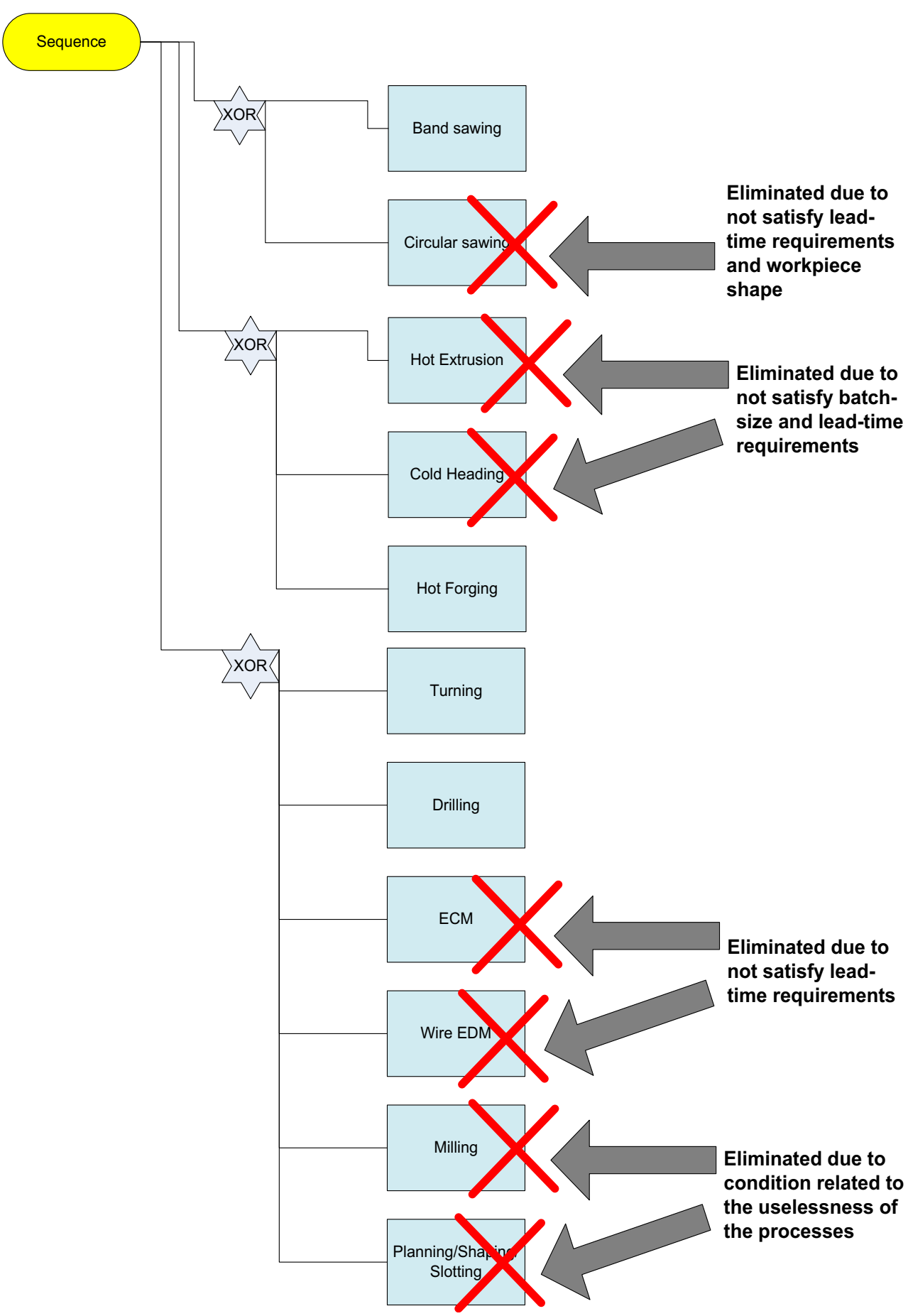


As can be seen from the output's software in manufacturing process selection, the part's functional surfaces are finished by machining processes in which turning and drilling processes are compatible with the part's specifications as shown in Figs. 11 and 12.

From the product's demands, the authors proposed three potential process plans which are eligible to manufacture the part. Furthermore, these process plans are successful candidates after applying the conditions to eliminate incompatible process plans as well as relying on the expert knowledge. They are visualized on the DELMIA's product-process-resource (PPR) screen.

As a result, machining simulation is operated with resources existing in the DELMIA's library such as machines
Fig. 14 Generating conceptual process plan 4

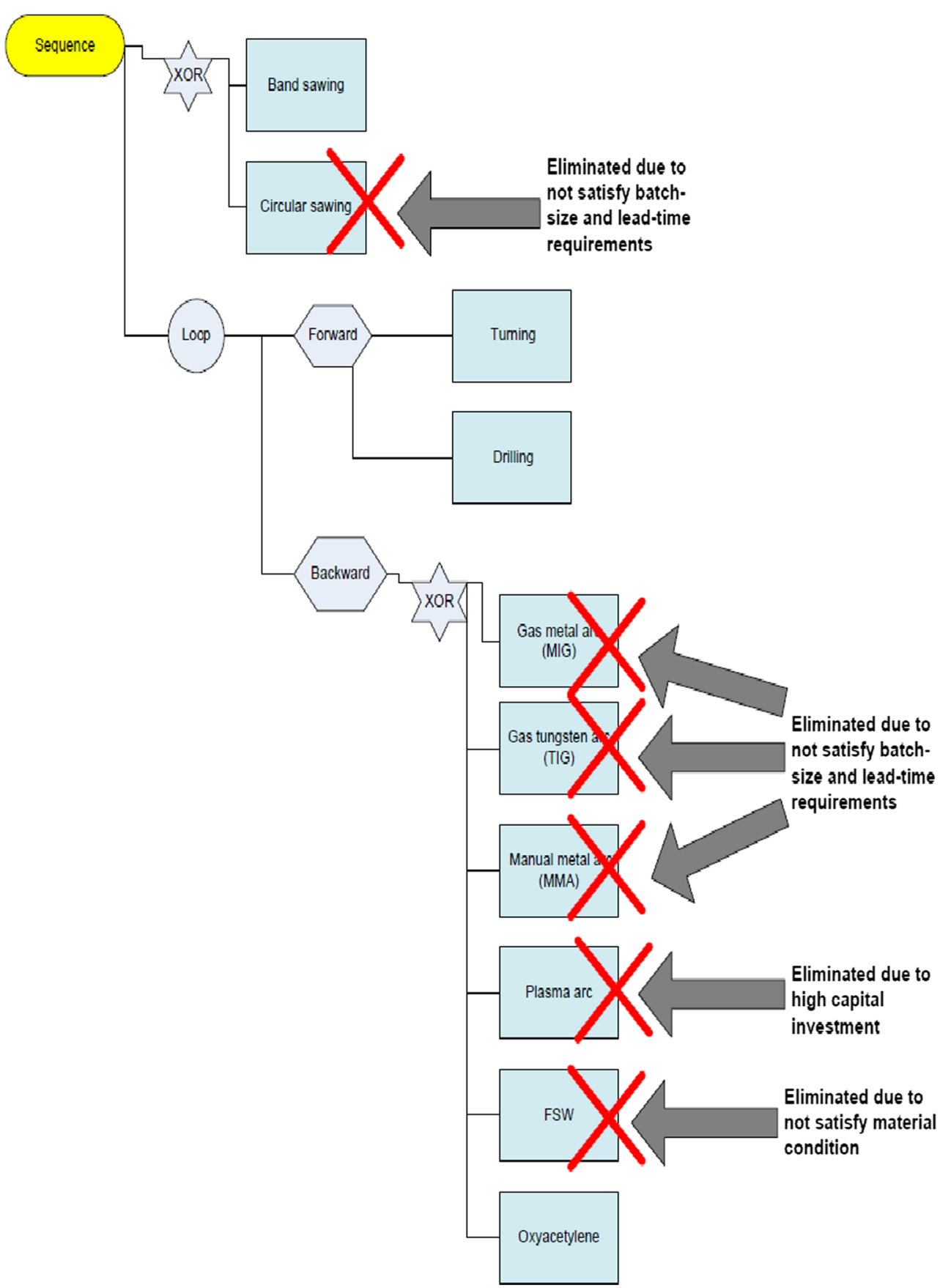


Fig. 15 Generating conceptual process plan 5

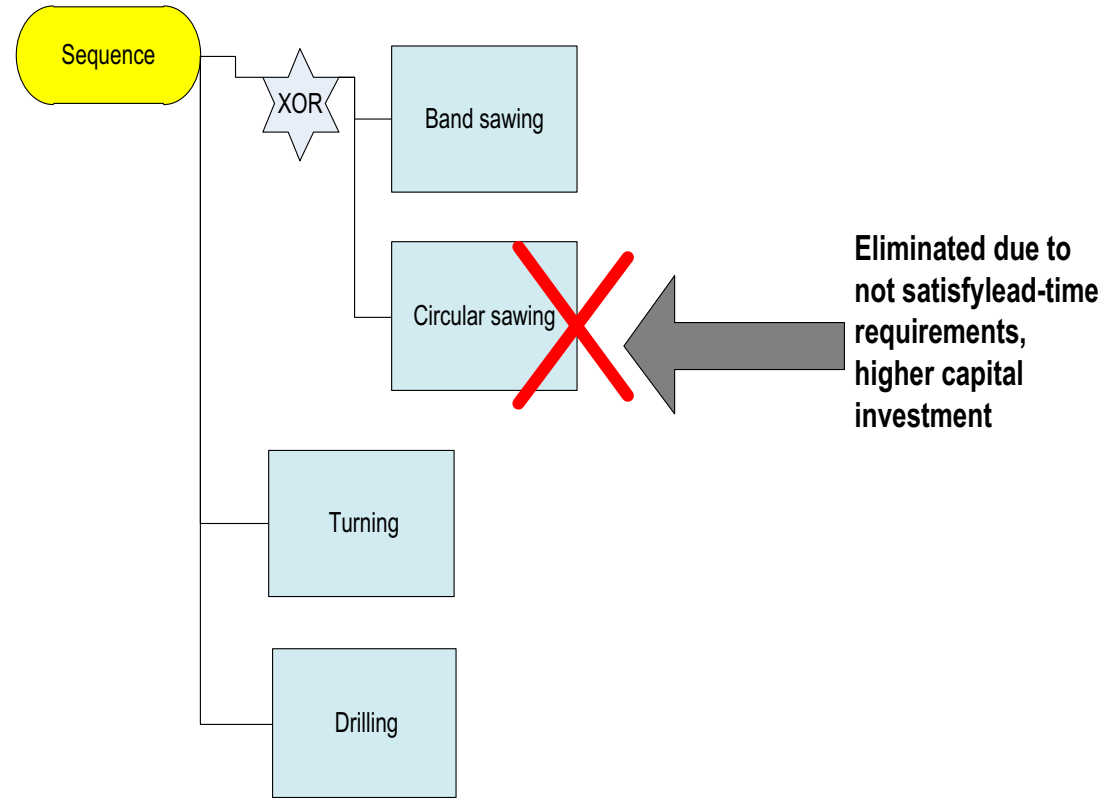

and tools in which cutting conditions are recommended from the online integrated cutting data module of Sandvik firm.

The process plan 2 (Fig. 13) is built from band sawing and forging processes for workpiece preparation, and drilling and turning for finishing the part, where circular sawing is eliminated due to not satisfying lead-time and workpiece requirements. Moreover, both hot extrusion and cold heading processes are eliminated because of conditions of elimination of lead time and batch size. Again, both ECM and wire EDM processes are eliminated due to lead time requirement.

Table 5 Synthesis of manufacturing process plans

\begin{tabular}{lc}
\hline Process & Processing time (min) \\
\hline Process plan 2 & \\
Sawing process & 18.5 \\
Close die forging process & 5.6 \\
Machining process & 19.106 \\
Total operation time & 43.206 \\
Process plan 4 & \\
Sawing process & 23.73 \\
Machining process & 39.01 \\
Welding process & 8.14 \\
Total operation time & 70.88 \\
Process plan 5 & \\
Sawing process & 18.5 \\
Machining process & 78.18 \\
Total operation time & 96.68 \\
\hline
\end{tabular}

Milling, planning, shaping, and slotting are removed due to the condition related to the uselessness of the processes.

Similarly, surface finishing in the process plan 4 is machined with turning and drilling processes. However, the part is separated into two components accounting for cylindrical component and disk component in this case.

Subsequently, the two components are welded together to complete the part. Likewise, conditions of elimination are applied for the process plan 4 shown on Fig. 14.

For process plan 5 (Fig. 15), band sawing is applied for cutting the workpiece from stock. Circular sawing is eliminated because of not satisfying lead time and higher capital investment requirements. Afterwards, the part would be finished by machining process in once fixture.

Scrutinized conceptual process plan 5 is created with PPR tree under DELMIA that served for simulation of virtual manufacturing process.

After simulating manufacturing process according to the three process plans for the forward steering part, manufacturing time is synthesized from the GANTT diagram, with the result as shown Table 5.

Table 6 Estimated manufacturing cost

\begin{tabular}{lrlllr}
\hline & $\begin{array}{l}\text { Sawing } \\
\text { process }\end{array}$ & $\begin{array}{l}\text { Machining } \\
\text { process }\end{array}$ & $\begin{array}{l}\text { Forging } \\
\text { process }\end{array}$ & $\begin{array}{l}\text { Welding } \\
\text { process }\end{array}$ & Totals \\
\hline Process plan 2 & 9.92 & 32.07 & 178.02 & $\mathrm{n} / \mathrm{a}$ & 220.01 \\
Process plan 4 & 15.66 & 43.16 & $\mathrm{n} / \mathrm{a}$ & 2.73 & 61.54 \\
Process plan 5 & 40.87 & 53.08 & $\mathrm{n} / \mathrm{a}$ & $\mathrm{n} / \mathrm{a}$ & 93.94 \\
\hline
\end{tabular}


Fig. 16 The AHP decision hierarchy for the decision

\section{Goal:}

Criteria:

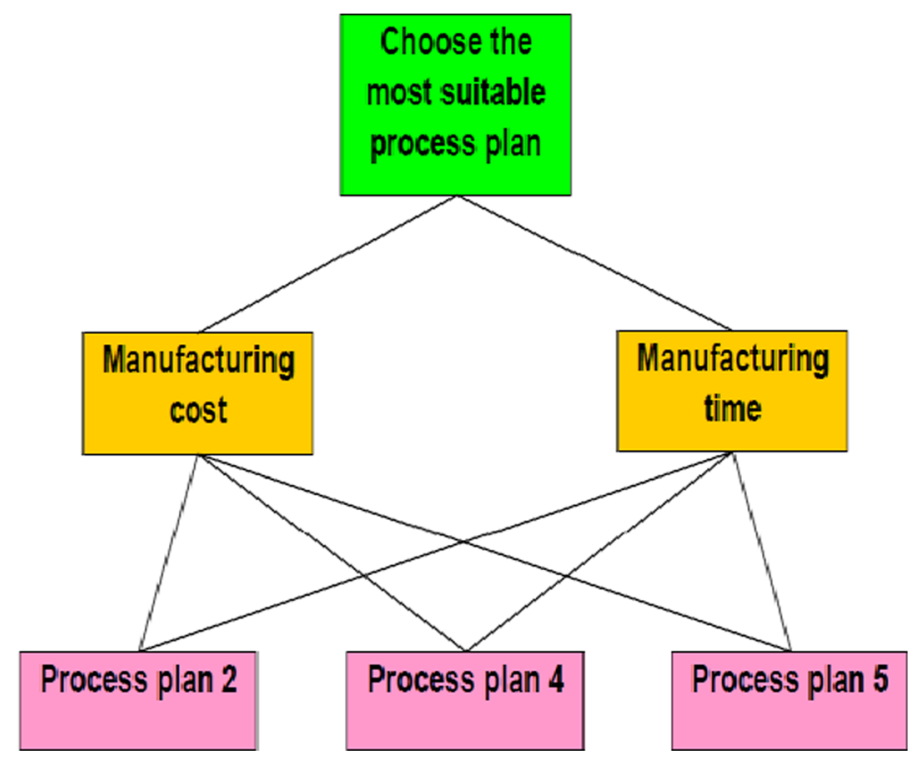

where

$D \quad$ Unique driver chosen for the cost entity

$\alpha_{R} \quad$ Resource $R$ consumption coefficient

$\mathrm{IR}_{r} \quad$ Resource $R$ imputation rate

As consequences of the calculations of each process plan, the total manufacturing and operations costs are synthesized as shown in Table 6.
$C_{\mathrm{ma}}=\sum_{i=1}^{N} C_{\text {activity }}^{i}$

In addition to that, each activity is estimated based on the cost entity approach was proposed by H'Mida [12]. Particularly, each cost entity is calculated in the following formula [12]:

$\operatorname{Cost} \mathrm{CE}=\mathrm{D} \times \sum\left(\alpha_{R} \times \mathrm{IR}_{r}\right)$

\section{Process plan selection}

In order to make a decision regarding the selection of the most suitable process plan, analytic hierarchy process (AHP) method is used with the goal, criteria, and alternatives as shown in Fig. 16.

Table 7 Judgment matrices with respect to the criteria

\begin{tabular}{|c|c|c|c|c|}
\hline \multicolumn{5}{|c|}{ The judgment matrix with respect to manufacturing cost } \\
\hline Manufacturing cost & Process plan 2 & Process plan 4 & Process plan 5 & Priority \\
\hline Process plan 2 & 1 & 0.28 & 0.43 & 0.14 \\
\hline Process plan 4 & 3.60 & 1.00 & 1.55 & 0.52 \\
\hline Process plan 5 & 2.37 & 0.66 & 1 & 0.34 \\
\hline \multicolumn{5}{|c|}{ The judgment matrix with respect to manufacturing time } \\
\hline Manufacturing time & Process plan 2 & Process plan 4 & Process plan 5 & Priority \\
\hline Process plan 2 & 1 & 1.70 & 2.30 & 0.49 \\
\hline Process plan 4 & 0.60 & 1.00 & 1.4 & 0.30 \\
\hline Process plan 5 & 0.43 & 0.71 & 1 & 0.21 \\
\hline
\end{tabular}


Table 8 Evaluation of the criteria in reaching the goal

\begin{tabular}{llll}
\hline Criteria & Manufacturing time & Manufacturing cost & Priority \\
\hline Manufacturing time & 1 & 0.33 & 0.23 \\
Manufacturing cost & 3.00 & 1.00 & 0.75
\end{tabular}

To support for decision makers, the judgment matrices consisting of weights in respect to manufacturing cost and manufacturing time between process plans as well as priorities of them are given in Table 7.

Note that pairwise comparisons are assigned the weights relied on the calculated results from the estimation of manufacturing time and manufacturing cost corresponding to the proposed process plans.

It is crucial for decision makers to evaluate the criteria with respect to their importance in reaching the goal through the matrix of comparison shown in Table 8.

After evaluation and analysis of the priorities between the alternatives, the criteria, and the goal, the final score of process alternative groups deduces the synthesized results shown in Table 9.

Based on the analyzed choice of decision criteria, it can be seen from Fig. 17 that the process plan 4 is the most suitable process plan for fabricating the steering pivot with the priority of 0.46 is higher than the others.

\section{Conclusion}

The works of this paper carried out are to tackle the issue in terms of the integration of the product's detailed design and the conceptual process plan in the early design stage by using numerical modeling and simulation. As a result, the most feasible process plan is extracted for the case study of the forward steering part. The advantages which get from this approach consisting of that we can foresee are the problems arising in manufacturing early and correcting the design as soon as possible. Consequently, lead time as well as the product's cost is decreased significantly. Furthermore, this approach contributes to collaborative design in which product

Table 9 The final score of alternatives

\begin{tabular}{llll}
\hline Alternative & Manufacturing cost & Manufacturing time & Goal \\
\hline Process plan 2 & 0.11 & 0.12 & 0.23 \\
Process plan 2 & 0.39 & 0.07 & 0.46 \\
Process plan 2 & 0.25 & 0.05 & 0.31 \\
Total & 0.75 & 0.25 & 1.00 \\
\hline
\end{tabular}

\section{The most suitable process plan}

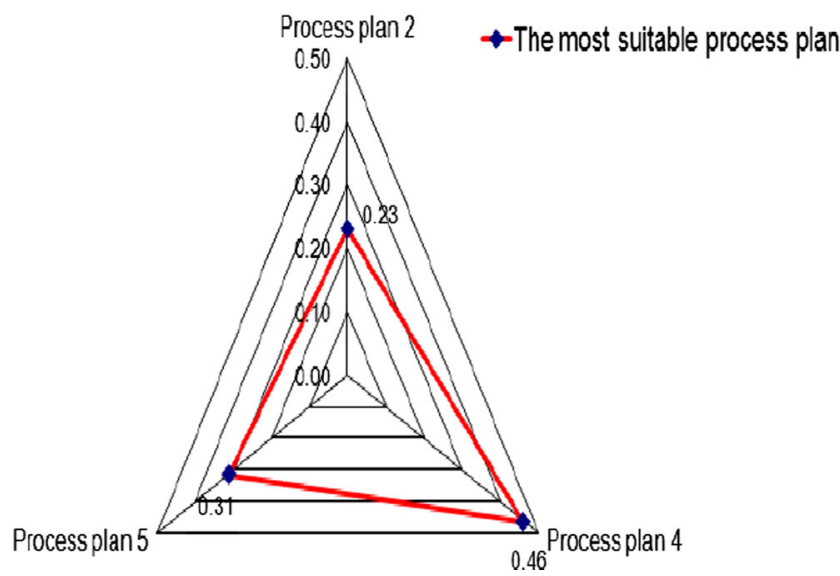

Fig. 17 The best choice for manufacturing the part

design and its manufacturing process information supporting for integrated design tools such as CAD/CAM and CAPP.

Nevertheless, a couple of issues are necessary to be taken into account in the future works. In the framework of this project, the quality function deployment (QFD) technique has not used to assess the process quality as well as FMEA has not carried out to assess failure modes and estimate failure cost [13]. Due to the fact that the defect rate is considered as $0 \%$ and the project has only considered the manufacturing time and cost of the conceptual process plans.

\section{References}

1. Sohlenius G (1992) Concurrent engineering. Ann CIRP 41:645-655

2. Boothroyd G, Dewhurst P, Knight W (1994) Product design for manufacture and assembly. Marcel Dekker, ISBN 0-8247-9176-2

3. Brissaud D, Paris H (1999) Co-operation in design: indicators as supports for the discussion between product and process engineers. In: Kals H, Van Houten F (eds) Integration of process knowledge into design support systems, pp 181-188, Kluwer academic publishers, ISBN 0-7923-5655-1

4. El Maraghy HA (1993) Evolution and future perspectives of CAPP. Ann CIRP 42(2):739-752

5. Eversheim W, Schulten I (1999) Optimal degree of parallelism and integration in design and process planning. In: Kals H, Van Houten F (eds) Integration of process knowledge into design support systems, Kluwer academic publishers, ISBN 0-7923-5655-1

6. Thibault A, Siadat A, Sadeghi M, Bigot R, Martin P (2009) Knowledge formalization for product-process integration applied to forging domain. Int J Adv Manuf Technol 44:1116-1132, Springer Verlag

7. Langlois L, Croué JB, Delamezière A, Martin P, Zimmer S (2012) Reconception de produit en intégrant les contraintes et les potentialités d'un procédé innovant : le FSW, 13e colloque national AIP PRIMECA, 28-30 March. Le Mont-Dore, France

8. Feng SC, Song EY (2003) A manufacturing process information model for design and process planning integration. J Manuf Syst 22:1

9. Ashby MF, Michael F (2004) Materials selection in mechanical design, Butterworth-Heinemann publishers, Oxford ISBN: 9780750643573 (0750643579) 
10. Villeneuve F, Barrabes M (1993) Object Data Base, AI and CAD-CAM : Application to the process ascending generation (PAG) concept, computers in design, manufacturing and production, 7th Annual European Computer Conference (IEEE), Compeuro 93, France, pp 320-329

11. Martin P, Dantan J-Y, Siadat A (2007) Cost estimation and conceptual process planning, digital enterprise technology, Springer Information Systems, ISBN 978-0-387-49863-8, 243-250
12. H'Mida F, Martin P, Vernadat F (2006) Cost estimation in mechanical production: the cost entity approach applied to integrated product engineering. Int J Prod Econ 103:17-35

13. Hassan A, Siadat A, Dantan J-Y, Martin P (2010) Conceptual process planning - an improvement approach using QFD, FMEA, and $\mathrm{ABC}$ methods. Robot Comput Integr Manuf 26: $392-401$ 